\title{
Relationship between Families Perception of Health and Support in the Care of Vulnerable Children
}

Chen $\mathrm{JY}^{1^{*}}$, Chen $\mathrm{HS}^{2}$, Liu $\mathrm{MC}^{3}$ and Chao $\mathrm{MC}^{4}$

${ }^{1}$ School of Nursing, Kaohsiung Medical University, Kaohsiung, Taiwan

${ }^{2}$ Pediatric Dentist, School of Dentist and Graduate Institute for Oral Health Science, Kaohsiung Medical University, Kaohsiung Medical University Hospital, Taiwan

${ }^{3}$ Department of Nursing, Kaohsiung Medical University Hospital, Taiwan

${ }^{4}$ School of Medicine, Kaohsiung Medical University; Department of Pediatrics, Division of Genetics, Endocrinology and Metabolism, \& Genetic Counseling Center, Kaohsiung Medical University Hospital, Taiwan

*Corresponding author: Jih Yuan Chen, College of Nursing, Kaohsiung Medical University, Kaohsiung, Taiwan, Tel: 011-886-7-3121101-2610; E-mail: jiyuch@kmu.edu.tw

Received date: July 27, 2015; Accepted date: September 21, 2015; Published date: September 28, 2015

Copyright: ( 2015 Chen et al. This is an open-access article distributed under the terms of the Creative Commons Attribution License, which permits unrestricted use, distribution, and reproduction in any medium, provided the original author and source are credited.

\begin{abstract}
Introduction: The role of family support in the care of vulnerable children is rarely discussed, yet has a major impact on family health. How family members' perceptions of their own health affect their vulnerable children has not been previously explored.

Purpose: The objectives of the study were to assess and compare the health status of perception using the Duke Health Profile (DUKE) and perceptions family support using the family APGAR (FAPGAR) across groups-families of children with muscular dystrophy, attention deficit hyperactivity disorders (ADHD), and chromosomal abnormality (Turner syndrome or Klinefelter syndrome, TS/KS).
\end{abstract}

Methods: The participants of the study were 286 from three cross-sectional studies from a southern medical hospital in Taiwan.

Results: This manuscript investigated the relationship between families' perception of health and support in the care of vulnerable children with DMD/SMA, ADHD, or TS/KS. By using multiple comparison, correlation and regression analysis, the authors reported that Duke Health Profile was significantly correlated with family support. Additionally, social health, age, marital status, and vulnerable status as predictors accounted for $35.3 \%$ of the variance in family support.

Discussion: Data suggest the efficacy to care for families of children as show in the DMD/SMA group, compared to ADHD and chromosome abnormality groups. The authors indicate that family support is critical in the care of vulnerable children. This study did provide some new information in the related field.

Keywords: Family health promotion; Family health; Family nursing; ADHD; DMD; SMA

\section{Introduction}

Families' perception of health and support is important to make positive functional resources in the care of vulnerable children. Vulnerable children in this study included the disabled children with Duchenne muscular dystrophy (DMD)/spinal muscular atrophy (SMA), attention deficit hyperactivity disorder (ADHD), or chromosome abnormality (Turner syndrome or Klinefelter syndrome, TS/KS). DMD/SMA is a primary genetic chronic disorder of motor and lung function and scoliosis by early muscle weakness that can lead to difficulties with walking, respiratory complications, and impact independence in daily activities [1,2]. ADHD is significant problems with attention and inhibitory control that cause attention deficits, hyperactivity, or impulsiveness with academic difficulties as are problems in relationship with family members [3]. TS/KS, a chromosome structure is altered and govern physical and medical characteristics, such as susceptibility to lymphedema, osteoporosis and fractures, structural malformations of the kidney, autoimmune thyroiditis, diabetes mellitus, inflammatory bowel disease [4-6], or higher risks for scoliosis, lordosis, and kyphosis [7].

The vulnerable situations have been found to exhibit relatively enduring health behavior, health values, family support, and health risk perceptions of families that can be developed and performed $[8,9]$, and situations of disability/worse health problem can compromise the independence and functional capacity of the vulnerable children thus making them dependent on caregivers, and inducing functional impairment in family, social, and academic settings that was similar in these groups of children and caused problems regarding families' health issues and general dysfunctional family support [10-14].

These untreated health problems may lead to major complications or complex limitations in activity and participation family time [4,15-18]. Policy programs for the vulnerable population were created and changed as generation change how that influenced families perception of their health and family support. However, empirical evidence to guide health professional collaborate with families to provide family health promotion intervention. Especially, disturbances 
in family function were related to a high risk of family depression $[8,10,12]$. Studies with parents of children with TS with depressive were associated with a poorer physical health and related to quality of life score (HRQoL) $[12,19]$. Family of children with ADHD also found higher conflict when compared with families of children without psychological illness [20]. Studies with family of children with ADHD found that anxiety was directly affecting caregiver health [13],family support was directly affecting caregiver health in family of children with ADHD or DMD [21,22]. Family support may be a critical early contribution to the risk of psycho-social pathology [23], but it is not recognized whether specific traits of family support may diversely contribute to different vulnerable types. More complex relationships between these variables have not been investigated.

Family support is implicated in families' satisfaction, receptiveness, responsiveness, and ability to take care of their children's needs. It also offered support to the family within a family unit for the care of a member with disabilities, as measured by constructs of the Family APGAR (FAPGAR), including adaptation, partnership, growth, affection, and resolve [24]. This study translated the FAPGAR into English means family caring index to measure of family members' satisfaction with the five aspects of family life. The role of these factors in the care of vulnerable children is rarely discussed, and no studies have explored aspects of family support in groups of children with vulnerable situations. The effect of family members' perceptions of their own health and family support on their own vulnerable children has received little examination in outpatient care settings.

\section{Purpose}

The aims of the study were to:

- assess families' perception of health associated with their children in different vulnerable care settings

- re-examine comparisons of families' perceptions of their own health and family support with a defined sample of vulnerable children in different vulnerable care settings

- explore the relative contribution of subscales of health variables and demographic variables correlated with caregivers/family members' family support in the care of vulnerable children.

\section{Methods}

\section{Design}

This study was a cross-sectional with self-report questionnaire analysis in the families of vulnerable children. The study was approved by the Institute Research board of KMUH (No.:2014058). All participants were volunteers and their anonymity was strictly maintained. The sample was a convenience sample that was referred by the hospitals' physicians or institute's social workers. The investigators informed the interviewees of the procedures, obtained their informed consent, and asked them complete the questionnaires after the caregivers agreed to participate in a family health promotion model survey. Completed questionnaires were returned to the research team using a prepaid envelope. A total of participants in 286 families including parents, caregivers, siblings, or even patients(over 20 years) were collected in outpatient clinics of pediatric and pediatric psychiatric in one hospital and one institute of muscular dystrophy association. Two major measurements addressed individual health status and family members' perceptions for satisfaction of their family support by the Duke Health Profile and the FAPGAR, and demographic questions for families with a DMD/SMA, ADHD, or TS/KS. Researchers would like to examine the gap of health and family support among above three groups and past periods to find the similar factors.

\section{Sample}

No missing data regarding both of the above mentioned measures (DUKE and FAPGAR) were included in the present study. The sample ranged in age from 20 to 64 years (mean $=41.47$ years, $\mathrm{SD}=8.83$ ). The representative sample consisted of 42 families of children with DMD $(\mathrm{n}=55$, mean age $=42.07, \mathrm{SD}=10.78), 44$ families of children with SMA $(n=58$, mean age $=43.33, S D=9.66), 96$ families of children with ADHD $(\mathrm{n}=109$, mean age $=40.46, \mathrm{SD}=6.27)$, and 43 families of children with $\mathrm{TS} / \mathrm{KS}(\mathrm{n}=64$, mean age $=41.06, \mathrm{SD}=9.74)$. Total of 225 families were from parents $(n=242,84.6 \%)$, sibling $(n=2,0.7 \%)$, patients $(n=32$, $11.2 \%)$, and caregivers $(\mathrm{n}=10,3.5 \%)$.

\section{Measures}

\section{Independent variables}

Differences were examined regarding vulnerable status, age, education, family monthly income, marital status (married, separated, divorce, single), living location (rural, town, urban, suburban), family structure (nuclear, expended, single, other), and power of decision (direct, indirect, silence, other). Means and standard deviations for families' general health and family support (including subscales) and $\mathrm{t} / \mathrm{F}$ values are presented.

\begin{tabular}{|c|c|c|c|c|c|}
\hline \multirow{2}{*}{$\begin{array}{l}\text { Subscale } \\
\text { Physical health }\end{array}$} & \multirow{2}{*}{$\begin{array}{l}\begin{array}{l}\text { Internal consistency reliability } \\
\text { (DMD/SMA, ADHD, and } \\
\text { Chromosome abnormality) } \\
\mathrm{N}=\mathbf{2 8 6}\end{array} \\
0.63\end{array}$} & \multirow{2}{*}{$\begin{array}{lr}\text { Internal } & \text { consistency } \\
\text { reliability } & \text { (DMD/SMA, 2012) } \\
\mathrm{N}=113 & \\
0.6\end{array}$} & \multicolumn{2}{|c|}{$\begin{array}{l}\text { Internal consistency reliability } \\
\text { (Paterson,1999;/Beaton,1997) }\end{array}$} & \multirow{2}{*}{$\begin{array}{l}\text { Internal consistency } \\
\text { reliability(ADHD, } \\
\text { 2012) } \mathrm{N}=109 \\
0.62\end{array}$} \\
\hline & & & 0.64 & 0.69 & \\
\hline Mental health & 0.65 & 0.57 & 0.52 & 0.42 & 0.63 \\
\hline Social health & 0.57 & 0.56 & 0.47 & 0.35 & 0.54 \\
\hline Self-esteem & 0.53 & 0.41 & 0.39 & 0.47 & 0.54 \\
\hline Perceived health & N/A & N/A & N/A & N/A & N/A \\
\hline
\end{tabular}


Citation: Chen JY, Chen HS, Liu MC, Chao MC (2015) Relationship between Families Perception of Health and Support in the Care of Vulnerable Children. Clinics Mother Child Health 12: 189. doi:10.4172/2090-7214.1000189

Page 3 of 10

\begin{tabular}{|l|l|l|l|l|l|}
\hline Pain & N/A & N/A & N/A & N/A & N/A \\
\hline Disability & N/A & N/A & N/A & N/A \\
\hline Anxiety & 0.61 & 0.56 & 0.52 & 0.68 & 0.53 \\
\hline Depression & 0.64 & 0.58 & 0.53 & 0.5 & 0.54 \\
\hline Anxiety-depression & 0.71 & 0.66 & 0.6 & 0.57 & 0.64 \\
\hline Duke Health Profile & 0.8 & 0.77 & 0.6 & 0.59 & 0.78 \\
\hline N/A: Not applicable & & & \\
\hline
\end{tabular}

Table 1: Comparison of reliability analysis of the Duke Health Profile between the current study and original.

\section{Duke Health Profile}

The measure is a survey constructed by Parkerson [25], 17-item instrument contains five positive functional health measures (physical, mental, social, self-esteem, and perceived health) and five negative functional health measures (pain, disability, anxiety, depression, and anxiety-depression). It used simple 3-response-options multi-item mean scores transformed to $0-2$ to 0 to 100 , for example $2=$ "yes, describes me exactly", 1="describes me somewhat", or $0=$ "no, does not describe me at all". Others were reported in the extent of difficultly experienced in an area " $0=\mathrm{a}$ lot, $1=$ some, or $2=$ none", or reported in terms of frequency during a one week " $2=\mathrm{a}$ lot, $1=$ sometimes, $0=$ none; or $2=$ none, $1=1-4$ days, $0=5-7$ days'. Higher scores on positive functional health indicated better health, and higher scores on negative functional health indicated worse health.

Table 1 showed the internal consistency reliability results of the subscales (0.53-0.71) of the Duke Health Profile overall (0.80) for this study and compared them with those reported by Parkerson et al. [26] and Beaton et al. [27].

\begin{tabular}{|c|c|c|c|c|c|c|c|c|c|c|}
\hline & \multicolumn{2}{|c|}{$\begin{array}{l}\text { Total DMD/SMA/ADHD/Chromosome } \\
\text { abnormality }\end{array}$} & \multicolumn{2}{|c|}{$\begin{array}{l}\text { Clinic A DMD (N: } \\
\text { 55)/SMA(N: 58) }\end{array}$} & \multicolumn{2}{|c|}{$\begin{array}{l}\text { Clinic B ADHD (N: } \\
\text { 109) }\end{array}$} & \multicolumn{2}{|c|}{$\begin{array}{l}\text { Setting } \\
\text { Chromosome } \\
\text { abnormality (N: 64) }\end{array}$} & \multirow[t]{2}{*}{ ANOVAF/ $p$} & \multirow[t]{2}{*}{$\begin{array}{l}\text { Post hoc test } \\
\text { Results/p } \\
\text { (method) }\end{array}$} \\
\hline & $\mathbf{N}$ & $\%$ & $\mathbf{N}$ & $\%$ & $\mathbf{N}$ & $\%$ & $\mathbf{N}$ & $\%$ & & \\
\hline \multicolumn{9}{|l|}{ Age } & $1.86 / 0.16$ & \\
\hline $20-30$ & 31 & 10.8 & 17 & 15 & 4 & 3.7 & 10 & 15.6 & & \\
\hline $31-40$ & 101 & 35.3 & 28 & 24.8 & 55 & 50.4 & 18 & 28.1 & & \\
\hline $41-50$ & 111 & 38.8 & 42 & 37.2 & 44 & 40.4 & 25 & 39.1 & & \\
\hline$>50$ & 43 & 15.1 & 26 & 22.6 & 6 & 5.5 & 11 & 17.2 & & \\
\hline \multicolumn{9}{|l|}{ Education } & $4.36 /<0.01$ & $\mathrm{C}>\mathrm{A} / 0.02(\mathrm{~T} 2)$ \\
\hline$\leq 9$ years & 50 & 17.5 & 31 & 27.5 & 13 & 11.9 & 6 & 9.4 & & \\
\hline 12 years & 106 & 37.1 & 38 & 33.6 & 50 & 45.9 & 18 & 28.1 & & \\
\hline 14 years & 69 & 24.1 & 20 & 17.7 & 30 & 27.5 & 19 & 29.7 & & \\
\hline$\geq 16$ years & 61 & 21.3 & 24 & 21.2 & 16 & 14.7 & 21 & 32.8 & & \\
\hline \multicolumn{9}{|c|}{ Family monthly income } & $8.95 /<0.01$ & $\mathrm{C}>\mathrm{B} / 0.01(\mathrm{~T} 2)$ \\
\hline$<20,000$ & 44 & 15.4 & 24 & 21.2 & 16 & 14.7 & 4 & 6.3 & & $\mathrm{C}>\mathrm{A} /<0.01(\mathrm{~T} 2)$ \\
\hline $\begin{array}{l}20,000-30,00 \\
0\end{array}$ & 36 & 12.6 & 15 & 13.3 & 17 & 15.6 & 4 & 6.3 & & \\
\hline $\begin{array}{l}30,000-40,00 \\
0\end{array}$ & 43 & 15 & 24 & 21.2 & 13 & 11.9 & 6 & 9.4 & & \\
\hline $\begin{array}{l}40,000-50,00 \\
0\end{array}$ & 26 & 9 & 9 & 8 & 11 & 10 & 6 & 9.4 & & \\
\hline $\begin{array}{l}50,000-60,00 \\
0\end{array}$ & 33 & 11.5 & 14 & 12.4 & 12 & 11 & 7 & 10.9 & & \\
\hline
\end{tabular}


Citation: Chen JY, Chen HS, Liu MC, Chao MC (2015) Relationship between Families Perception of Health and Support in the Care of Vulnerable Children. Clinics Mother Child Health 12: 189. doi:10.4172/2090-7214.1000189

Page 4 of 10

\begin{tabular}{|c|c|c|c|c|c|c|c|c|c|c|}
\hline$>60,000$ & 93 & 32.5 & 16 & 14.2 & 40 & 36.7 & 37 & 57.7 & & \\
\hline \multicolumn{9}{|c|}{ Marriage status } & $6.48 /<0.01$ & $\mathrm{~B}>\mathrm{A} /<0.01(\mathrm{~T} 2)$ \\
\hline Married & 220 & 76.9 & 78 & 69 & 96 & 88.1 & 46 & 71.9 & & $\mathrm{~B}>\mathrm{C} / 0.04(\mathrm{~T} 2)$ \\
\hline Separated & 3 & 0.1 & 2 & 1.8 & 0 & 0 & 1 & 1.5 & & \\
\hline Divorce & 21 & 7.3 & 8 & 7.1 & 10 & 9.2 & 3 & 4.7 & & \\
\hline Single & 42 & 14.7 & 25 & 22.1 & 3 & 2.7 & 14 & 21.9 & & \\
\hline \multicolumn{9}{|c|}{ Resilience location } & $2.12 / 0.12$ & \\
\hline Rural & 54 & 18.9 & 34 & 30.1 & 13 & 11.9 & 7 & 10.9 & & \\
\hline Town & 73 & 25.5 & 22 & 19.4 & 5 & 4.6 & 46 & 71.9 & & \\
\hline Urban & 145 & 50.7 & 57 & 50.4 & 80 & 73.4 & 8 & 12.5 & & \\
\hline Suburban & 14 & 4.9 & 0 & 0 & 11 & 10.1 & 3 & 4.7 & & \\
\hline \multicolumn{9}{|c|}{ Family structure } & $2.29 / 0.10$ & \\
\hline Nuclear & 202 & 70.6 & 73 & 64.6 & 78 & 64.6 & 51 & 79.7 & & \\
\hline Expended & 45 & 15.7 & 29 & 25.7 & 18 & 25.7 & 8 & 12.5 & & \\
\hline Single & 17 & 5.9 & 6 & 5.3 & 7 & 5.3 & 4 & 6.3 & & \\
\hline Other & 12 & 4.2 & 5 & 4.5 & 6 & 9.8 & 1 & 1.6 & & \\
\hline \multicolumn{9}{|c|}{ Power of decision } & $4.26 / 0.02$ & $\mathrm{C}>\mathrm{B} / 0.01(\mathrm{~T} 2)$ \\
\hline Direct & 214 & 74.8 & 80 & 70.8 & 78 & 71.5 & 56 & 87.5 & & $\mathrm{C}>\mathrm{A} /<0.01(\mathrm{~T} 2)$ \\
\hline Indirect & 58 & 20.3 & 25 & 22.1 & 25 & 22.9 & 8 & 12.5 & & \\
\hline Silence & 8 & 2.8 & 5 & 4.4 & 3 & 2.8 & 0 & 0 & & \\
\hline Other & 6 & 2.1 & 3 & 2.7 & 3 & 2.8 & 0 & 0 & & \\
\hline
\end{tabular}

Table 2: Aggregated families demographics by clinics and setting for the entire study period ( $\mathrm{N}=286)$.

Table 2 presents the characteristics of the participants and their family. Participants were female $(66.1 \% ; \mathrm{N}=169)$, married $(76.8 \%$,
$\mathrm{N}=220$ ), over two thirds had completed education over 12 years, whose monthly income was over 30000, and primary living at urban or town

\begin{tabular}{|c|c|c|c|c|c|}
\hline \multirow[t]{3}{*}{ Subscale } & Research 1 & \multirow{2}{*}{$\begin{array}{l}\text { Research } 2 \\
\text { Clinic B: ADHD ( } N=109)\end{array}$} & Research 3 & \multirow{2}{*}{ ANOVA F/p } & \multirow{2}{*}{ 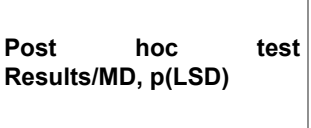 } \\
\hline & $\begin{array}{l}\text { Clinic } \\
(\mathrm{N}=113)\end{array} \quad \mathrm{A}: \quad \mathrm{DMD} / \mathrm{SMA}$ & & $\begin{array}{l}\text { Setting C: Chromosome } \\
\text { abnormality }(\mathrm{N}=64)\end{array}$ & & \\
\hline & $\mathrm{M} / \mathrm{SD}$ & M/SD & $\mathrm{M} / \mathrm{SD}$ & & \\
\hline \multirow[t]{2}{*}{ Physical health } & $56.90 / 22.24$ & $64.50 / 19.36$ & $70.00 / 18.73$ & $8.57 / 0.00$ & $\mathrm{~B}>\mathrm{A} / 7.59,<0.01$ \\
\hline & & & & & $\mathrm{C}>\mathrm{A} / 12.26,<0.01$ \\
\hline \multirow[t]{2}{*}{ Mental health } & 61.50/18.62 & $64.95 / 22.26$ & $72.90 / 20.68$ & $6.09 / 0.01$ & $\mathrm{C}>\mathrm{B} / 7.70,0.02$ \\
\hline & & & & & $C>A / 11.15,<0.01$ \\
\hline \multirow[t]{2}{*}{ Social health } & $65.75 / 20.12$ & $66.15 / 18.80$ & $72.26 / 18.85$ & $2.88 / 0.06$ & $\mathrm{C}>\mathrm{B} / 6.35,0.04$ \\
\hline & & & & & $\mathrm{C}>\mathrm{A} / 6.74,0.03$ \\
\hline \multirow[t]{2}{*}{ Self-esteem } & $67.43 / 18.07$ & $69.08 / 18.18$ & $75.00 / 19.31$ & $3.42 / 0.03$ & $\mathrm{C}>\mathrm{B} / 5.76,0.05$ \\
\hline & & & & & $\mathrm{C}>\mathrm{A} / 7.41,0.01$ \\
\hline
\end{tabular}


Citation: Chen JY, Chen HS, Liu MC, Chao MC (2015) Relationship between Families Perception of Health and Support in the Care of Vulnerable Children. Clinics Mother Child Health 12: 189. doi:10.4172/2090-7214.1000189

Page 5 of 10

\begin{tabular}{|l|l|l|l|l|l|}
\hline Perceived health & $59.29 / 36.32$ & $69.27 / 34.63$ & $73.39 / 29.64$ & $4.16 / 0.02$ & $\mathrm{~B}>\mathrm{A} / 9.97,0.03$ \\
\hline & & & & & $\mathrm{C}>\mathrm{A} / 14.14,0.01$ \\
\hline Pain & $45.58 / 30.29$ & $40.83 / 30.55$ & $35.48 / 26.22$ & $1.91 / 0.15$ & \\
\hline Disability & $13.27 / 28.36$ & $9.63 / 23.05$ & $5.65 / 20.46$ & $2.07 / 0.13$ & \\
\hline Anxiety & $37.24 / 17.15$ & $34.86 / 20.98$ & $30.78 / 18.45$ & $2.31 / 0.10$ & $\mathrm{~A}>\mathrm{C} / 6.38,0.03$ \\
\hline Depression & $40.71 / 18.45$ & $37.98 / 23.48$ & $31.61 / 18.92$ & $3.92 / 0.02$ & $\mathrm{~A}>\mathrm{C} / 8.98,0.01$ \\
\hline Anxiety-depression & $38.81 / 17.42$ & $36.89 / 21.15$ & $30.76 / 19.17$ & $3.62 / 0.03$ & $\mathrm{~B}>\mathrm{C} / 6.09,0.05$ \\
\hline & & & & $\mathrm{A}>\mathrm{C} / 8.01,0.01$ \\
\hline \begin{tabular}{l} 
Duke Health Profile \\
\hline
\end{tabular} & $62.75 / 15.04$ & $66.67 / 14.77$ & $73.15 / 15.42$ & $9.65 / 0.01$ & $\mathrm{C}>\mathrm{B} / 6.38,0.01$ \\
\hline $\begin{array}{l}\text { A: DMD/SMA group } \\
\text { B: ADHD group } \\
\text { C: Chromosome abnormality group }\end{array}$ & & & & $\mathrm{C}>\mathrm{A} / 10.27,<0.01$ \\
\hline
\end{tabular}

Table 3: Subscales of the Duke health profile by clinics and setting for the total study.

\section{Dependent variable}

Family APGAR. The FAPGAR contained five items to measure five dimensions, adaptability, partnership, growth, affective, and resolve, using a 3-point Likert scale ranged from 0-hardly ever, 1-some of time, to 2-almost always [24,28]. Scores ranged from 0-10, with a higher score indicating greater satisfaction with family support. The Cronbach's alpha $(0.88)$ indicated feasibility to be used in clinical settings.

\section{Data analysis}

Data analyses were performed using SPSS 21. Descriptive statistics were used to examine families' perception of health and family support in children with different diseases. Multiple Comparison analyses among three clinical or institute settings were examined using ANOVA. Pearson correlations were utilized to analyze relationship among health and family support variables and demographic variables. Contributing predictors were analyzed utilizing multiple regressions.

\section{Results}

Table 2 presents the characteristics of the participants and their family. Participants were female $(66.1 \% ; \mathrm{N}=169)$, married $(76.8 \%$, $\mathrm{N}=220$ ), over two thirds had completed education over 12 years, whose monthly income was over 30000 , and primary living at urban or town. Approximately three quarters of family structure were nuclear and directly power to propose idea or plan (76\%). There were no significant differences in characteristics in age, resilience location, and family structure among three groups. Table 2 also presented significant differences in education, family monthly income, marital status, and power decision between the three groups of vulnerable children.

Table 3 shows significant differences between clinics/setting are noted for the all subscales of all positive functional health and the higher scores reported negative functional health fell into family pain category for the ADHD and the TS/KS group. The higher scores reported positive functional health fell into the family self-esteem for DMD/SMA or TS/KS. Different presented with ADHD depicting the higher scores fell into the family perceived health. Among the participants, based on mean differences TS/KS had higher scores selfesteem, social health, and mental health than ADHD group or DMD/SMA group. ADHD group had higher scores physical health and perceived health than the DMD/SMA group, but that were lower scores than TS/KS. DMD/SMA group had higher scores anxiety, depression, and anxiety-depression than TS/KS group, ADHD group had a higher score anxiety-depression than TS/KS group. TS/KS group had a higher score overall Duke Health score than DMD/SMA or ADHD group (Table 3).

Table 4 presents all participants' self-esteem received the highest score and the second highest score was social health. Significant differences among the three study period/different samples are found for the subscales of physical health, perceived health, and overall score (Table 4). Compared to literature in 2007 for DMD group, it expressed significantly greater to increase physical health and overall Duke Health scores, but no significant differences among the three study periods/ different samples for all subscales of negative functional health (Table 4).

\begin{tabular}{|c|c|c|c|c|c|}
\hline \multirow[b]{2}{*}{ Subscale } & Research A & Research B & Research C & \multirow[b]{2}{*}{ ANOVA F/p } & \multirow{2}{*}{$\begin{array}{l}\text { Post hoc test } \\
\text { Results/MD, p(LSD) }\end{array}$} \\
\hline & $\begin{array}{l}\text { Mean/SD DMD/SMA, } \quad \text { ADHD, } \\
\text { Chromosome abnormality ( }=286)\end{array}$ & $\begin{array}{l}\text { Mean/SD } \quad \text { DMDI } \\
\text { SMA, } 2012(\mathrm{~N}=113)\end{array}$ & $\begin{array}{l}\text { Mean/SD Chen and Clark, } \\
2007(N=126)\end{array}$ & & \\
\hline Duke Health Profile & $66.54 / 15.40$ & $62.75 / 15.04$ & $67.48 / 15.79$ & $3.26 / 0.04$ & $A>B / 3.35,0.03$ \\
\hline
\end{tabular}


Citation: Chen JY, Chen HS, Liu MC, Chao MC (2015) Relationship between Families Perception of Health and Support in the Care of Vulnerable Children. Clinics Mother Child Health 12: 189. doi:10.4172/2090-7214.1000189

Page 6 of 10

\begin{tabular}{|l|l|l|l|l|l|}
\hline & & & & & C>B/43.16, 0.02 \\
\hline Physical & $62.62 / 20.94$ & $56.90 / 22.24$ & $66.11 / 19.51$ & $5.90 /<0.01$ & $\mathrm{~A}>\mathrm{B} / 5.36,0.01$ \\
\hline & & & & & $\mathrm{C}>\mathrm{B} / 9.21,<0.01$ \\
\hline Mental health & $64.97 / 20.07$ & $61.50 / 18.62$ & $64.13 / 19.73$ & $1.45 / 0.23$ & \\
\hline Social health & $67.41 / 20.07$ & $65.75 / 20.12$ & $65.16 / 21.23$ & $0.66 / 0.52$ & \\
\hline Self-esteem & $69.72 / 18.56$ & $67.43 / 18.07$ & $71.51 / 21.51$ & $1.34 / 0.26$ & \\
\hline Perceived health & $66.26 / 34.64$ & $59.29 / 36.32$ & $78.17 / 34.93$ & $9.11 /<0.01$ & $\mathrm{C}>\mathrm{A} / 12.08,<0.01$ \\
\hline & & & & $\mathrm{C}>\mathrm{B} / 18.88,<0.01$ \\
\hline Pain & $41.78 / 29.81$ & $45.58 / 30.29$ & $43.25 / 26.35$ & $0.70 / 0.50$ & \\
\hline Disability & $10.14 / 20.07$ & $13.27 / 28.36$ & $7.94 / 19.40$ & $1.43 / 0.24$ & \\
\hline Anxiety & $35.20 / 18.24$ & $37.24 / 17.15$ & $33.93 / 19.53$ & $0.99 / 0.37$ & \\
\hline Depression & $38.01 / 19.80$ & $40.71 / 18.45$ & $37.62 / 20.33$ & $1.02 / 0.36$ & \\
\hline Anxiety-depression & $36.54 / 18.86$ & $38.81 / 17.42$ & $35.37 / 18.75$ & $1.08 / 0.34$ & \\
\hline $\begin{array}{l}\text { A: DMD/SMA, ADHD, and chromosome abnormality group } \\
\text { B: DMD/SMA group at 2012 } \\
\text { C: DMD group at 2007 }\end{array}$ & & & & \\
\hline
\end{tabular}

Table 4: Subscales of the Duke health profile by authors for the total sample.

Among the components of FAPGAR in this study, resolve received the highest score, and adaptation received the second highest score. The other components are listed in descending order of score, i.e., affection, growth, and partnership. Table 5 shows the overall scores of family support and their subscales at different settings/clinics for families of children with different types of diseases. Significant differences in family support score, subscale of adaptation, and partnership score are found between setting/clinics. The mean differences from highest to lowest were in partnership and in adaptation among three types of vulnerable groups. However, compared to literature in 2007 DMD group or the TS/KS group had lower adaptation than the DMD/SMA group (Table 5).

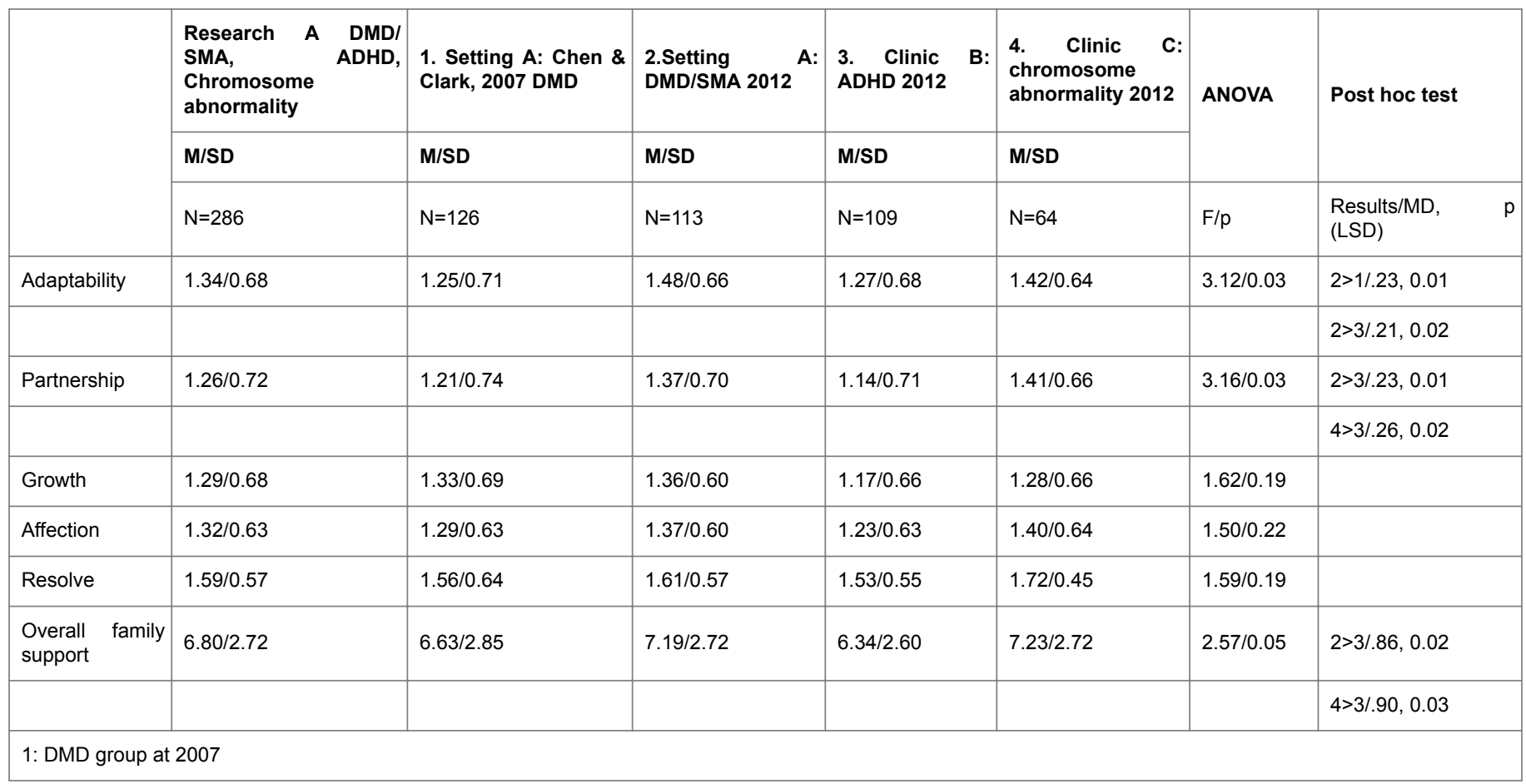


Citation: Chen JY, Chen HS, Liu MC, Chao MC (2015) Relationship between Families Perception of Health and Support in the Care of

\section{2: DMD/SMA group at 2012}

3: ADHD group at 2012

4: Chromosome abnormality group at 2012

Adaptation: caregivers/families are satisfied that they can turn to my family for help when something is troubling them

Partnership: caregivers/ families are satisfied with the way their family talks over things with them and shares problems with them

Growth: caregivers/families are satisfied that their family accepts and supports their wishes to take on new activities or directions

Affection: caregivers/ families are satisfied with the way their family expresses, affection, and responds to their emotions, such as anger, sorrow, or love Resolve: caregivers/families are satisfied with the way their family and they share time together

Table 5: Total Family Apgar compared by clinics/authors.

\section{Preliminary analysis}

Intercorrelations among all variables, marital status, monthly income, occupation, education level, and family structure were related to overall health $(\mathrm{r}=0.12-0.30 ; \mathrm{p}=0.01-0.05)$. Marital status was positively related to physical and perceived health $(\mathrm{r}=0.17-0.21$; $p=0.01$ ). Family structure was positively related to mental and social health, and self-esteem $(\mathrm{r}=0.12-0.15 ; \mathrm{p}=0.01-0.04)$; however, it was negatively related to anxiety, depression, and anxietydepression( $\mathrm{r}=-0.14 \sim-0.17 ; \mathrm{p}=0.010 .02)$. Monthly income was positively related to physical, mental, and social health, and selfesteem, perceived health $(\mathrm{r}=0.20-0.25, \mathrm{p}=0.01)$; and it was negatively related to disability, anxiety, depression, and anxiety-depression $(\mathrm{r}=-0.18-0.25, \mathrm{p}=0.01)$.

For identified factors of overall health or subscales of health associated with family support before determining the contributing predictors of family support, we found that total scores of family support, including subscales, were significantly positive for subscales of positive functional health $(\mathrm{r}=0.24$ to $0.50, \mathrm{p}=0.001)$, and significantly negative correlated with family support for subscales of negative functional health ( $\mathrm{r}=-0.15$ to $-0.40, \mathrm{p}=0.001-0.013)$, and exhibited higher positive correlation for overall health $(\mathrm{r}=0.49, \mathrm{p}=0.001)$. In addition, there were no significant correlations found between marital status $(\mathrm{r}=0.12, \mathrm{p}=0.51)$, resilience locations $(\mathrm{r}=-0.04, \mathrm{p}=0.95)$, and family structure $(\mathrm{r}=0.09, \mathrm{p}=0.15)$ with family support. But gender $(\mathrm{r}=0.161, \mathrm{p}=0.006)$ and monthly income $(\mathrm{r}=0.127, \mathrm{p}=0.031)$ exhibited significantly correlation with family support.

\section{Regressions}

Hierarchical multiple regressions were performed to determine the relative contribution of subscales of health variables correlated with caregivers/family members' family support (Table 6).

\begin{tabular}{|c|c|c|c|c|c|c|c|c|c|c|c|}
\hline No. & Model & B & SE & $\beta$ & $\begin{array}{l}\mathrm{CL} \\
\text { bound) }\end{array}$ & $\begin{array}{l}\mathrm{CL} \text { (upper- } \\
\text { bound) }\end{array}$ & $t(p)$ & $\mathbf{R}$ & R2 & $\Delta \mathbf{R}^{2}$ & $\mathbf{F}$ \\
\hline \multirow[t]{3}{*}{1} & Constant & 1.073 & 0.593 & & -0.095 & 2.24 & $1.808(0.072)$ & 0.542 & 0.249 & 0.282 & $23.353^{*}$ \\
\hline & Mental health & 0.024 & 0.01 & 0.188 & 0.005 & 0.043 & $2.462(0.004)$ & & & & \\
\hline & Social health & 0.038 & 0.012 & 0.28 & 0.015 & 0.061 & $3.271(0.001)$ & & & & \\
\hline \multirow[t]{2}{*}{2} & Constant & 3.65 & 2.254 & & -0.787 & 8.086 & $1.620(0.106)$ & 0.553 & 0.305 & 0.28 & $12.094^{*}$ \\
\hline & Social health & 0.039 & 0.013 & 0.286 & 0.014 & 0.065 & $3.038(0.003)$ & & & & \\
\hline \multirow[t]{5}{*}{3} & Constant & 1.236 & 2.318 & & -3.328 & 5.8 & $0.533(0.594)$ & 0.594 & 0.353 & 0.312 & $8.593^{*}$ \\
\hline & Social health & 0.04 & 0.013 & 0.291 & 0.015 & 0.065 & $3.108(0.002)$ & & & & \\
\hline & Age & -0.694 & 0.308 & -0.13 & -1.301 & -0.087 & $-2.250(0.025)$ & & & & \\
\hline & Marital status & 0.937 & 0.388 & 0.149 & 0.174 & 1.7 & $2.418(0.016)$ & & & & \\
\hline & Vulnerable status & 0.101 & 0.031 & 0.175 & 0.04 & 0.162 & $3.257(0.001)$ & & & & \\
\hline
\end{tabular}

Table 6: Results of final model of family health and demographic variables on family support.

In step 1, family support was the dependent variable and all positive functional healthy variables were the independent variables, and were entered into the regression. Result showed that the positive functional healthy variables including mental health and social health $(\beta=0.19$ and $0.28 ; \mathrm{p}=0.01$ ) accounted for $29 \%$ of the family support variance. In step 2, all negative functional health variables were added to the equation, only social health contributed significantly to the regression equation $(\beta=0.29, p=0.01)$. In step 3 , demographic variables (age, vulnerable status, family monthly income, occupation, marital status, family structure, and family development) were added to the equation, four variables including social health and demographic variables (age, vulnerable status, and marital status) accounted for $35.3 \%$ of the family support variance. Adjusted variance attributable to these variables was 0.312 , which was significantly different from zero, F17, $268=8.593$, $\mathrm{p}=0.001$. 


\section{Discussion}

The paper explored the measurement properties of scales used to measure participants' health and family support in southern Taiwan. The results of this study indicated that the Duke Health Profile and the Family APGAR constituted self-reported scales with available psychometric properties exhibiting internal consistency. Individuals in the three groups perceived lower scores in the subscales of mental health, social health, self-esteem, and overall health than the TS/KS group. Moreover, physical and perceived health received lower scores in the DMD/SMA group compared with the ADHD or the TS/KS group. In contrast to the families' perception of health noted in the literature, the DMD group reported higher scores in physical health, perceived health, and overall health [29] than the DMD/SMA group in 2012, which received higher scores in the above three groups of this study. And was also higher than the DMD/SMA or the ADHD group, and that reported in previous studies in 1999 [26] and 1997 [27], except for physical health. In addition, received self-esteem the highest score and social health received the second highest score, which was the same as that of the DMD/SMA group's families in 2012. In 2007, parents of children with DMD received the highest perceived health score, and received self-esteem the second higher score among subscales of the Duke [29]. Similar results comparing three study periods/different samples were found on subscales of negative functional health. It may support parents of children with disabilities has stress that may link to child behavior disturbances, limitations in child function, and families demands [30].

The reason for the self-reported lower scores of subscales of positive functional health for all participants and higher scores were reported (indicating worse health status) in anxiety, depression, and anxietydepression in the DMD/SMA group than the TS/KS group. It is associated with medical technique and health delivery systems that have improved to the lifespan of children with muscular dystrophy [22,31]. This is because as children's ages increase and there is a gradual increased immobility and transportation limitations, and ultimately death, all of which combine to produce physical and mental overload for families the care of children with muscular dystrophy increasingly depends on families to take care of their worsening condition $[6,22,32]$. Therefore, overload causes families to report lower scores (worse health) in all positive functional health variables in the DMD/SMA group than the ADHD or the TS/KS group. In addition, higher score of anxiety-depression indicated worse health in the ADHD group than the TS/KS group. This result was similar to Cussen [33] and Theule et al. [34] who found that parents of children with ADHD had more parental depression, anxiety, and higher stress levels that were a result of their child's ADHD symptoms. However, there were no significant differences in reporting subscales' scores of negative functional health in different study periods.

Knussen and Sloper [35] reported that parenting stress of children with disability was influenced by social support, marital satisfaction, and financial resources. Murphy et al. [36] recommended that parental stress of children with epilepsy went up as the child's physical, social, school, and emotional function increases not related to a child's disability itself but to other parent, family, and social factors. However, our findings showed that marital status was not associated with depression, anxiety, and family support, which is inconsistent with previous studies [35,37]. The marital status of the participants was significantly associated with better physical health, perceived health, and overall health, which is consistent with previous studies indicating that married people enjoying better physical health $[37,38]$.
Participants living in a nuclear family perceived better mental, social, and perceived health; however, they perceived less anxiety, depression, and anxiety-depression. The nuclear families try to problem-solve together and support each other and have more stable relationships. Families who had higher monthly income reported perceived better physical, mental, social, and perceived health, and self-esteem as well as they reported lower scores in disability, anxiety, depression, and anxiety-depression.

In addition, DMD/SMA groups reported higher scores in adaptability than the ADHD group and for 2007 DMD group [29] and Nan et al. [19] family residents in Hong Kong However, the ADHD group reported lower scores in partnership and overall family support than the DMD group, the TS/KS group, and Nan et al. [19] group. Correlation between family support and demographic variables were expressed male and higher monthly income families who had reported higher family support.

From hierarchical multiple regressions analysis, the large effect for social health then vulnerable status, marital status, and age as well entered in the final regression model showed that four predictors accounting for $35.3 \%$ of the variance in family support. The family role with satisfied marital status and age differences might make their health and support different. Vulnerable populations who are less likely to have a usual source of care if they are poorer or lack insurance or age increased [39]. Usual source of care provide for the vulnerable groups may promote their health care qualities and maintain their family support to facilitate their families health.

\section{Limitations}

The present study was still not representative of families of vulnerable children, as the sample used was not random. No data were recorded regarding the reason for non-participation, however, it was assumed that these people wanted to maintain their privacy and they were busy. Future research might employ composite scales to assess health, wellbeing, and family support measures and with larger samples using that integrate quantitative and qualitative methods toward development outcome based program research and incorporate practitioner perspective for evidence based practice.

\section{Implications for policy and practice}

The results suggest the efficacy to care for families of children regarding their physical health, mental health, self-esteem, and perceived health, and reducing anxiety, depression or anxietydepression as shown in the DMD and SMA group, compared to the ADHD and the TS/KS families. It is critically important for health promotion strategies to provide the DMD/SMA and the ADHD families with comparatively more resources than the TS/KS families.

Social health was an important contributor to family support, which was highly positively correlated with overall health and subscales of positive health. Maintaining and increasing social and family support actions that were focused on as age increase, poor income, and activity severely limitation would be able to create a higher quality of life and resolve family health promotion problems to enable positive family function for the specify participants.

\section{Acknowledgement}

We would like to thank Dr. Cheng-Fang Yen, Dr. Pin-Chen Yang, Dr. Joel Stocker, and the families of children with DMD, SMA, ADHD, 
and Chromosome abnormalities for their contribution to the completion of this research. We are also grateful for the generous funding support from KMUH (KMUH-N10004, N10005, and N10006).

\section{Contributions}

Study design: JYC; data collection and analysis: MCL, MCC; and manuscript preparation: JYC, HSC, MCC.

\section{Conflict of Interest}

The authors declare no competing interests.

\section{Ethical Approval}

Details of information brochure and informed consent were approved by KMUH IRB board (KMUH-IRB-2014058).

\section{References}

1. Amundson E, Boman UW, Barrenäs ML, Bryman I, Landin-Wilhelmsen K (2010) Impact of growth hormone therapy on quality of life in adults with turner syndrome. J Clin Endocrinol Metab 95: 1355-1359.

2. Bondy CA, Turner Syndrome Consensus Study Group (2007) Care of girls and women with Turner syndrome: A guideline of the Turner syndrome study group. Journal of Clinical Endocrinology \& Metabolism 92: 10-25.

3. Byers DJ, Wicks MN, Beard TH (2011) Depressive Symptoms and Health Promotion Behaviors of African-American Women Who Are Family Caregivers Of Hemodialysis Recipients. Nephrology Nursing Journal 38: 425-431.

4. Cano A, Scaturo DJ, Sprafkin RP, Lantinga LJ, Fiese BH, et al. (2003) Family support, self-rated health, and psychological distress. Primary Care Companion J Clin Psychiatry 5: 111-115.

5. Chaves CB, Amarala OP, Nelasa PA, Coutinhoa EC, Dionisiob RM (2013) Assessment of family functionality among the elderly with chronic illness. European Journal of Counselling Psychology 2.

6. Chen JY, Clark MJ (2007) Family function in families of children with Duchenne muscular dystrophy. Fam Community Health 30: 296-304.

7. Chen JY, Clark MJ (2010) Family resources and parental health in families of children with Duchenne muscular dystrophy. J Nurs Res 18: 239-248.

8. Chen JY, Clark MJ, Chang YY, Liu YY (2015) Anxiety, Decision Conflict, and Health in Caregivers of Children with ADHD: A Survey. J Pediatr Nurs 30: 568-579.

9. Chen JY, Chen SS, Jong YJ, Yang YH, Lue YJ (2013) Psychosocial stress and coping strategies of parents with duchenne muscular dystrophy children during the middle stage. In: Angelini C (ed.) Muscular Dystrophy: Causes and Management. Nova, Newyork, pp. 339-356.

10. Chen JY, Chao MC, Yang SY, Xiao YH, Lin YH (2014) Family resource and health perspective of children with Turner syndrome: A model testing. 8th INP/APNN Conference 2014: Advanced nursing practice: Expanding access and improving healthcare outcome. Helsinki, Finland.

11. Chen JY, Clark MJ, Chang YY, Liu YY, Chang CY (2014) Factors affecting perceptions of family function in caregivers of children with attention deficit hyperactivity disorders. J Nurs Res 22: 165-175.

12. Cussen A, Sciberras E, Ukoumunne OC, Efron D (2012) Relationship between symptoms of attention-deficit/hyperactivity disorder and family functioning: a community-based study. Eur J Pediatr 171: 271-280.

13. Davenport ML (2010) Approach to the patient with Turner syndrome. J Clin Endocrinol Metab 95: 1487-1495.

14. Di Pinto D, Balestracci A, Dujovne N, de Palma I, Adragna M, et al. (2010) [Nephrourologic pathology in girls with Turner syndrome]. Arch Argent Pediatr 108: 353-357.
15. Dobbertin K, Horner-Johnson W, Lee JC, Andresen EM (2015) Subgroup differences in having a usual source of health care among working-age adults with and without disabilities. Disabil Health J 8: 296-302.

16. Ginsberg Y, Quintero J, Anand E, Casillas M, Upadhyaya HP (2014) Underdiagnosis of attention-deficit/hyperactivity disorder in adult patients: a review of the literature. Prim Care Companion CNS Disord 16: e1-e8.

17. Goldacre MJ, Seminog OO (2014) Turner syndrome and autoimmune diseases: record-linkage study. Arch Dis Child 99: 71-73.

18. Haldeman-Englert C (2013) Duchenne muscular dystrophy. MedlinePlus Medical Encyclopedia.

19. Heo S, Lennie TA, Moser DK, Kennedy RL (2014) Types of social support and their relationships to physical and depressive symptoms and healthrelated quality of life in patients with heart failure. Heart Lung 43: 299-305.

20. Huang YC, Tsai YC (2011) [Empowering the family-center health model: the toy library as a health promotion platform]. Hu Li Za Zhi 58: 16-23.

21. Iezzoni LI, Frakt AB, Pizer SD (2011) Uninsured persons with disability confront substantial barriers to health care services. Disabil Health J 4: 238-244.

22. Ishikawa Y, Miura T, Ishikawa Y, Aoyagi T, Ogata H, et al. (2011) Duchenne muscular dystrophy: survival by cardio-respiratory interventions. Neuromuscul Disord 21: 47-51.

23. Jørgensen KT, Rostgaard K, Bache I, Biggar RJ, Nielsen NM, et al. (2010) Autoimmune diseases in women with Turner's syndrome. Arthritis Rheum 62: 658-666.

24. Knussen C, Sloper P (1992) Stress in families of children with disability: A review of risk and resistance factors. Journal of Mental Health 1: 241-256.

25. Lovelan-Cherry CJ, Bomar PJ (2004) Family health promotion and health protection. In: Bomar PJ (ed.) Promoting health in families: applying family research and theory to nursing practice. Saunders, Philadelphia.

26. Murphy, Caplin DA, Christian BJ, Luther BL, Holobkov R, et al. (2011) The function of parents and their children with cerebral palsy. PM R 3: 98-104.

27. Nan H, Lee PH, Ni MY, Chan BH, Lam TH (2013) Effects of depressive symptoms and family satisfaction on health related quality of life: the Hong Kong FAMILY study. PLoS One 8: e58436.

28. NIH (2015) Chromosome abnormalities: National Human Genome Research Institute.

29. Ogburn KM, Sanches M, Williamson DE, Caetano SC, Olvera RL, et al. (2010) Family environment and pediatric major depressive disorder. Psychopathology 43: 312-318.

30. Olszewska E, Wiśniewski A, Madej M, Trzcińska D, Tabor P, et al. (2010) [Posture in Turner Sundrome Patients]. Paediatr Endocrinol Diabetes Metab16: 189-195.

31. Park JC, Choi YS, Lee WK, Kim SH, Kim JA, et al. (2005) Depression and anxiety trend according to family function in children. J Korean Acad Fam Med 26: 536-543.

32. Parkerson GRJ (ed.) (2002) User's guide for Duke Health Measures Durham, NC: Department of Community and Family Medicine, Duke University Medical Center, Durham, NC.

33. Raina P, O'Donnell M, Rosenbaum P, Brehaut J, Walter SD, et al. (2005) The health and well-being of caregivers of children with cerebral palsy. Pediatrics 115: e626-636.

34. Smilkstein G (1978) The family APGAR: a proposal for a family function test and its use by physicians. J Fam Pract 6: 1231-1239.

35. Smilkstein G, Ashworth C, Montano D (1982) Validity and reliability of the family APGAR as a test of family function. J Fam Pract 15: 303-311.

36. Staton J (2008) What is the Relationship of Marriage to Physical Health?: National healthy marriage resource center.

37. Sybert VP, McCauley E (2004) Turner's syndrome. N Engl J Med 351: 1227-1238. 
Citation: Chen JY, Chen HS, Liu MC, Chao MC (2015) Relationship between Families Perception of Health and Support in the Care of Vulnerable Children. Clinics Mother Child Health 12: 189. doi:10.4172/2090-7214.1000189

Page 10 of 10

38. Theule J, Wiener J, Rogers M, Marton I (2011) Predicting parenting stress in families of children with ADHD: Parent and contextual factors. Journal of Child \& Family Studies 20: 640-647.
39. Wikimedia Foundation (2015) Spinal muscular atrophy in Foundation W, ed. 